\title{
GESTÃO AMBIENTAL E A EFETIVAÇÃO DO "PROGRAMA MUNICÍPIO VERDEAZUL": UM ESTUDO COMPARATIVO ENTRE OS MUNICÍPIOS DE BILAC E GABRIEL MONTEIRO
}

\author{
Gabriela lassia Finati, Cintia de Toro Sato \\ Universidade Estadual de Londrina - UEL, Mestrado em Geografia, Departamento de Geociências, Londrina, PR. \\ Universidade do Oeste Paulista - UNOESTE, Especialização em Comunicação Empresarial e Marketing Digital, \\ Presidente Prudente, SP. E-mail: gabriela.iassia@gmail.com
}

\section{RESUMO}

Este artigo trata de um estudo comparativo entre dois municípios do noroeste paulista, Bilac e Gabriel Monteiro, em relação à gestão ambiental no período de 2008 a 2016, de modo a verificar quais as ações realizadas pelo poder público municipal que contribuíram para a classificação de ambas no ranking da Certificação do Programa Município VerdeAzul. O estudo compreende uma catalogação das leis aprovadas no período, relacionadas aos temas estabelecidos nas avaliações, sendo estes: Esgoto Tratado, Resíduos Sólidos, Biodiversidade, Arborização Urbana, Educação Ambiental, Cidade Sustentável, Gestão das Águas, Qualidade do Ar, Estrutura Ambiental e Conselho Ambiental. A partir de uma pesquisa bibliográfica e verificação de leis aprovadas nesse período foi possível verificar quais as ações realizadas compreendem propostas de mitigação ou adaptação e que contribuíram para determinar a pontuação e inclusão no ranking de Município VerdeAzul.

Palavras-chave: Programa Município VerdeAzul, Gestão ambiental, Bilac, Gabriel Monteiro.

\section{ENVIRONMENTAL MANAGEMENT AND THE IMPLEMENTATION OF "PROGRAMA MUNICÍPIO VERDEAZUL": A COMPARATIVE STUDY BETWEEN THE COUNTIES OF BILAC AND GABRIEL MONTEIRO}

\begin{abstract}
This article deals with a comparative study between two counties in the northwest of São Paulo, Bilac and Gabriel Monteiro, in relation to environmental management in the period from 2008 to 2016, in order to verify which actions carried out by the municipal public authority contributed to the classification of both In the ranking of the Certification of the "Programa Município VerdeAzul". The study includes a cataloging of laws approved in the period related to the themes established in the evaluations, such as: Treated Sewage, Solid Waste, Biodiversity, Urban Forestry, Environmental Education, Sustainable City, Water Management, Air Quality, Environmental Structure and Environmental Council. Based on a bibliographical research and verification of laws approved during this period, it was possible to verify which actions were carried out included proposals for mitigation or adaptation and that contributed to determine the score and inclusion in the ranking of "Município VerdeAzul".

Keywords: Programa Município VerdeAzul, Environmental management, Bilac, Gabriel Monteiro.
\end{abstract}

\section{INTRODUÇÃO}

As cidades são apropriadas e negociadas diariamente. Mais do que o lugar onde são realizadas as ações de consumo, elas são também a própria mercadoria, o objeto de consumo. $A$ cidade é, pois, resultado do trabalho humano e onde pode-se perceber a produção dos valores e 
ideias de cada sociedade. Com a urbanização, o espaço urbano torna-se onde a própria natureza é urbanizada e negociada.

A sociedade é, portanto, parte integrante dos espaços urbanos, e tem o poder de fazer destes um espaço vivo ou apagado, além de transformá-los e caracterizá-los de acordo com a necessidade atual, seja ela econômica ou não. Pensar em cidade é pensar que cada uma possui sua particularidade e dificilmente, consegue-se aplicar as mesmas ações de modo a torná-las eficazes. De certa forma, isso ocorre, pois o ambiente é um campo heterogêneo e conflituoso em que diversos saberes e interesses se confrontam em busca de um desenvolvimento sustentável (LEFF, 2007).

Em relação ao desenvolvimento sustentável, bem como a preocupação com a qualidade de vida urbana pelas administrações das cidades, ambos têm sido intensificados após a década de 1960, como afirma Mendonça (2004) devido a explosão demográfica e crescente urbanização. Desde então, diversos são os temas abordados pelos ambientalistas, perpassando desde assuntos relacionados ao "desmatamento, do buraco na camada de ozônio, da poluição industrial, dos agrotóxicos na agricultura" (MARANDOLA, 2014) e a partir do ano de 2007, as mudanças climáticas têm ocupado o papel principal nas discussões.

Segundo dados da Secretaria do Meio Ambiental do Estado de São Paulo (2017), em 2007, o Governo do Estado de São Paulo lançou o programa Município VerdeAzul (PMVA), um projeto que visa descentralizar a política ambiental e enfatizar a importância do meio ambiente bem como da gestão hídrica, e tem como objetivo auxiliar os municípios para que se desenvolvam de maneira sustentável, além de executar as políticas públicas de maneira estratégica.

Atualmente 645 municípios aderiram ao programa e ressalta-se que a participação é um dos critérios para liberação dos recursos do Fundo Estadual de Controle da Poluição - FECOP, que conforme o Art. 1ㅇda Lei no 11.160/2002 é um “ Fundo de Financiamento e Investimento vinculado à Secretaria do Meio Ambiente, destinado a apoiar e incentivar a execução de projetos relacionados ao controle, à preservação e à melhoria das condições do meio ambiente no Estado."

Para que o município seja certificado, é necessário que o Índice de Avaliação Ambiental IAA seja 80, autenticando o desempenho relacionado às diretivas (GOVERNO DE SÃO PAULO, 2016). O Programa Município Verde e Azul propõe ações que compõem as dez diretivas que orientam a gestão ambiental municipal, apresentadas a seguir:

Quadro 1. Diretivas e Objetivos fundamentais do Programa Município VerdeAzul

\begin{tabular}{|l|l|}
\hline \multicolumn{1}{|c|}{ Diretivas } & \multicolumn{1}{|c|}{ Objetivos fundamentais } \\
\hline Esgoto Tratado & $\begin{array}{l}\text { Ampliar os índices de coleta, transporte, tratamento e disposição, de } \\
\text { forma adequada, dos esgotos urbanos }\end{array}$ \\
\hline Gestão das Águas & $\begin{array}{l}\text { Fortalecer a gestão municipal sobre a qualidade da água, especialmente a } \\
\text { destinada a abastecimento público. }\end{array}$ \\
\hline Resíduos Sólidos & $\begin{array}{l}\text { Fortalecer a gestão dos resíduos sólidos domiciliares e da construção civil, } \\
\text { de programas ou ações de coleta seletiva e da responsabilidade pós- } \\
\text { consumo. }\end{array}$ \\
\hline Cidade Sustentável & $\begin{array}{l}\text { Aumentar o grau de consciência e compromisso em torno das práticas de } \\
\text { desenvolvimento sustentável, como forma de diminuir as } \\
\text { vulnerabilidades, conferindo resiliência e propiciando o bem-estar e } \\
\text { segurança dos cidadãos. }\end{array}$ \\
\hline Biodiversidade & $\begin{array}{l}\text { Proteger e/ou recuperar/restaurar áreas estratégicas para a manutenção } \\
\text { dos recursos naturais. }\end{array}$ \\
\hline Arborização Urbana & $\begin{array}{l}\text { Incrementar a gestão do meio ambiente urbano por meio do } \\
\text { planejamento e definição de prioridades para a arborização urbana. }\end{array}$ \\
\hline
\end{tabular}

Colloquium Socialis, Presidente Prudente, v. 01, n. Especial 2, Jul/Dez, 2017, p.786-793. DOI: 10.5747/cs.2017.v01.nesp2.s0229 


\begin{tabular}{|l|l|}
\hline Educação Ambiental & $\begin{array}{l}\text { Implementar a Educação Ambiental no âmbito formal e informal em três } \\
\text { eixos: formação, capacitação e mobilização da comunidade }\end{array}$ \\
\hline Qualidade do Ar & $\begin{array}{l}\text { Implementar atividades e participar de iniciativas que contribuam para a } \\
\text { manutenção ou melhoria da qualidade do ar e do controle da emissão } \\
\text { excedente de gases de efeito estufa. }\end{array}$ \\
\hline Estrutura Ambiental & $\begin{array}{l}\text { Estimular o fortalecimento das Secretarias/ Departamentos/ Diretorias de } \\
\text { Meio Ambiente. }\end{array}$ \\
\hline Conselho Ambiental & $\begin{array}{l}\text { Estimular o funcionamento regular dos Conselhos Municipais de Meio } \\
\text { Ambiente. }\end{array}$ \\
\hline
\end{tabular}

Fonte: Governo do Estado de São Paulo, adaptado pelas autoras, 2017

As dez diretivas que compõem o projeto consistem em medidas de mitigação ou adaptação, responsáveis por propor a minimização da devastação dos recursos ambientais. Cabe destacar a diferença entre o conceito de mitigar e adaptar utilizados neste trabalho:

A primeira se refere à paliativos, a ajustes de conduta ou de eficiência de processos para diminuir as emissões de Gases de Efeito Estufa (GEE) ou implementando capacidades de resposta em áreas e populações em risco. A segunda envolve a revisão de modelos de desenvolvimento, substituição de tecnologias e de processos (cadeias produtivas inteiras, se for o caso), visando alterar a relação sociedade-ambiente na sua base. É óbvio que as primeiras são preferidas em relação às segundas, pois dependem menos recursos e não implicam em mudanças substanciais no status quo (MARANDOLA, 2014, p. 101).

A partir disso pretende-se verificar no período de 2008 a 2016, ou seja, desde o início do Programa VerdeAzul até a última classificação quais foram as medidas adotadas por duas gestões municipais, Bilac e Gabriel Monteiro, e que contribuíram para que seus municípios obtivessem determinados resultados.

\section{METODOLOGIA}

Para a escolha dos municípios a serem comparados e analisados determinou-se alguns critérios de modo a elencá-los entre todos os municípios do Estado de São Paulo que aderiram ao longo desses oito anos as avaliações. Primeiramente, foi determinado que a análise seria feita a partir da comparação de dois municípios. Em seguida, optou-se pela escolha de um município certificado no último ranking e outro não certificado, que possuíssem densidade populacional semelhante, pertencessem a duas Unidades de Gerenciamento de Recursos Hídricos distintos e no entanto, fossem próxima uma das outras.

Bilac e Gabriel Monteiro são, portanto, os dois municípios escolhidos para a análise e comparação por se tratarem de dois municípios que se enquadram na escala de pequenos municípios, a primeira com aproximadamente 7048 hab. e a segunda 2708 hab. e pela proximidade que se encontram uma da outra. No entanto embora sejam cidades limítrofes cada uma pertence a uma Unidade de Gerenciamento de Recursos Hídricos, a primeira ao Baixo Tietê e a segunda a Aguapeí-Peixe (Figura 1). Isso permite identificar como as estratégias ambientais são tratadas e se desenvolvem nessas duas unidades distintas. 
Figura 1: Unidade Gerenciadora de Recursos Hídricos 19 e 20, com destaque para os municípios de Bilac e Gabriel Monteiro.

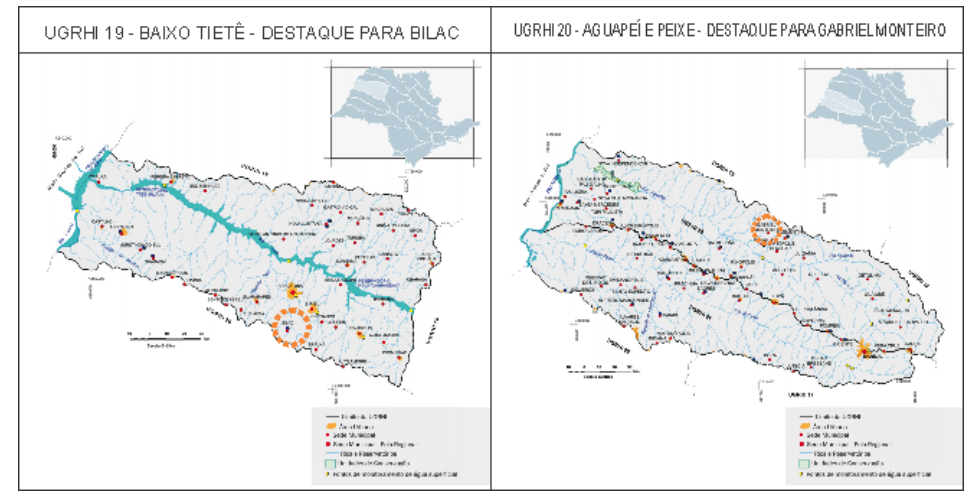

Fonte: Portal SigRH (Sistema Integrado de Gerenciamento de Recursos Hídricos do Estado de São Paulo), modificado pelas autoras, 2017

Com o objetivo de analisar as ações do poder público do município de Bilac e Gabriel Monteiro, no período de 2008 a 2016, e traçar um quadro comparativo das ações realizadas pelas duas gestões municipais, que contribuíram para a inclusão ou não inclusão de ambas na lista de municípios certificados pelo governo estadual, realizou-se uma pesquisa bibliográfica, fundamentada em registros de pesquisas anteriores e de informações de outros livros, artigos e pesquisadores (GIL, 2002). Além disso, leis relacionadas às questões ambientais avaliadas pelo Programa foram listadas de modo a verificar se elas possuem relação com a pontuação.

\section{RESULTADOS}

Essa etapa do trabalho consiste em verificar a pontuação obtida ao longo dos anos e elencar leis e decretos, de modo a identificar sua relação com a pontuação. Não serão listados leis e decretos federais e estaduais, somente municipais, com o intuito de verificar as ações particulares de cada um.

No Quadro 2 estão dispostas as leis do município de Bilac e Gabriel Monteiro que estabelecem parâmetros relacionados às questões ambientais, de 2013 a 2016, disponíveis para a consulta da população através do portal da Câmara Municipal de cada município.

Quadro 2. Leis - Bilac e Gabriel Monteiro (2013-2016)

\begin{tabular}{|c|c|c|}
\hline ANO & LEIS - BILAC & LEIS - GABRIEL MONTEIRO \\
\hline \multirow[t]{3}{*}{2013} & $\begin{array}{l}\text { Lei n. } 1.909 / 2013 \text {, de } 27 \text { de junho de } \\
2013 \text { - Institui o Plano Diretor de } \\
\text { Arborização Urbana e dá outras } \\
\text { providências }\end{array}$ & \\
\hline & $\begin{array}{l}\text { Lei n. } 1.952 / 2013 \text {, de } 23 \text { de dezembro de } \\
2013 \text { - Dispõe sobre a Política Municipal } \\
\text { de Saneamento Ambiental e dá outras } \\
\text { providências. }\end{array}$ & \\
\hline & $\begin{array}{l}\text { Lei n. 1.956/2013, de } 23 \text { de dezembro de } \\
2013 \text { - Institui o Código Municipal de } \\
\text { Resíduos Sólidos e dá outras providências }\end{array}$ & \\
\hline 2014 & & $\begin{array}{l}\text { Lei n. 1.820/2014 de } 25 \text { de agosto de } 2014 \text { - } \\
\text { Autoriza a Prefeitura Municipal de Gabriel } \\
\text { Monteiro a instituir o "Programa Municipal } \\
\text { de Pagamentos por Serviços Ambientais "e } \\
\text { estabelecer convênios com o Estado de São }\end{array}$ \\
\hline
\end{tabular}




\begin{tabular}{|l|l|l|}
\hline 2015 & $\begin{array}{l}\text { Lei n. 2.058/2015, de 17 de março de } \\
2015 \text { - Autoriza o Município celebrar } \\
\text { convênio com o Estado de São Paulo, } \\
\text { através da Secretaria de Saneamento e } \\
\text { Recursos Hídricos, e dá o outras } \\
\text { providências. }\end{array}$ & $\begin{array}{l}\text { Lei n. 1.854/2015 de 10 de agosto de 2015 - } \\
\text { Institui o plano municipal de gerenciamento } \\
\text { integrado de resíduos sólidos do município } \\
\text { de Gabriel Monteiro - PMGRS e dá outras } \\
\text { providências. }\end{array}$ \\
\hline 2016 & $\begin{array}{l}\text { Lei n. 2.119/2016 de 7 de junho de 2016 - } \\
\text { Dispõe sobre multa por dano ambiental e } \\
\text { dá outras providências }\end{array}$ & $\begin{array}{l}\text { Projeto de lei n. 020/2016 de 12 de maio de } \\
\text { 2016 - Dispõe sobre a criação do conselho } \\
\text { Municipal de Saneamento Ambiental e dá } \\
\text { outras providências. }\end{array}$ \\
\hline
\end{tabular}

Fonte: Câmara Municipal de Bilac e Gabriel Monteiro, elaborado pelas autoras, 2017

Embora o início do Programa seja em 2008, ambos os municípios concentram-se em criar leis relacionadas às diretivas apenas a partir de 2013, no caso de Bilac e em 2014, Gabriel Monteiro. É possível verificar no quadro acima que ambos possuem legislações que regulamentam o Plano de Gerenciamento de resíduos sólidos, o saneamento ambiental e também o convênio com o Estado de São Paulo na aplicação de outras ações e multas por danos ambientais.

A partir dessas leis listadas acima, o município de Bilac contempla as diretivas de arborização urbana, Esgoto Tratado, Resíduos sólidos, Estrutura ambiental e Conselho Ambiental. Já Gabriel Monteiro, Esgoto Tratado, Resíduos sólidos, Cidade Sustentável, Educação ambiental, Estrutura ambiental e Conselho Ambiental.

Embora haja um crescimento na determinação e proposição de novas leis, algumas ações não são pontuadas pelo Programa por não possuírem comprovação da efetivação das mesmas. Por outro lado, caso o município não possua a lei que regulamente a ação, mas ele executa e comprova a mesma, há a pontuação. A Figura 2 mostra as pontuações finais dos dois municípios desde 2008.

Figura 2: Ranking - 2008 a 2016 de Bilac e Gabriel Monteiro - Programa Município VerdeAzul.

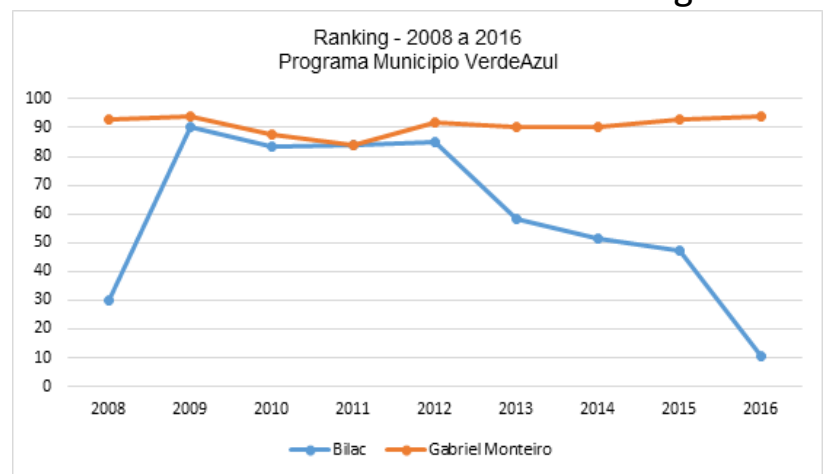

Fonte: Adaptado do Governo do Estado de São Paulo, 2017

Desse modo, através da análise comparativa entre os dois municípios estudados, pode-se perceber que desde a criação do programa, o município de Gabriel Monteiro se manteve certificado, ou seja, seguiu as diretivas e critérios estabelecidos, garantindo recursos. Já o município de Bilac só se certificou no período de 2009 a 2012, evidencia-se que há a possibilidade de que o município de Bilac não tenha priorizado o programa devido a troca de gestão, visto que em Gabriel Monteiro a gestão continuou a mesma e o município se manteve certificado. 
Portanto ao longo dos 8 anos, a pontuação de Gabriel Monteiro não variou radicalmente, em contrapartida, a partir de 2013, o município de Bilac teve sua pontuação reduzida, mesmo com a criação de leis que dispõe sobre o meio ambiente e urbanidade.

\section{DISCUSSÃO}

Embora Bilac possua um número maior de leis no período analisado, Gabriel Monteiro manteve sua pontuação maior. Pode-se notar que as leis de Gabriel Monteiro contemplam, como é o caso do Plano Municipal de Gerenciamento Integrado de Resíduos Sólidos, não somente uma diretiva, mas a união de duas ou mais. Desse modo, essas ações partem para uma solução mais efetiva, pois não buscam apenas a mitigação de determinado ponto e sim a adaptação do conjunto como um todo, visando resultados a longo prazo.

Através da análise das leis foi possível distinguir, portanto, quais são as medidas mitigadoras e quais são medidas de adaptação. Em relação ao município de Bilac, a Lei no 1.909/2013 trata-se de uma medida de mitigação pois aborda o planejamento, a implantação e manejo da arborização urbana, visando a melhoria de qualidade de vida e equilíbrio ambiental

Já o saneamento ambiental disposto na Lei no 1.952/2013 é uma medida de prevenção pois tende a reduzir impactos negativos e consequências catastróficas por meio de projetos que ampliem serviços e ações de saneamento básico, programas de educação ambiental e sanitária, além de adotar tecnologias para saneamento básico e desenvolver ações integradas para concretização de sistema de drenagem sustentável. Para Carvalho (2015) um dos desafios à prevenção, é que aparentemente os riscos não são notáveis, porém geram grandes perdas no ecossistema, ou seja, muitas vezes a sociedade não percebe de maneira efetiva, os impactos que determinadas atitudes geram ao ambiente.

Ainda no ano de 2013 foi sancionada a Lei no 1.956 que instituiu o código municipal de resíduos sólidos, que também refere-se a uma medida de prevenção, pois estabeleceu diretrizes para a destinação adequada dos resíduos, sendo proibida a destinação e queima a céu aberto.

Em 2015, o município celebrou convênio com o Estado de São Paulo, através da Secretaria de Saneamento e Recursos Hídricos para a perfuração de um poço tubular profundo, caracterizando uma medida adaptativa, porém a obra não foi executada até o momento. Posteriormente, no ano de 2016 foi promulgada a Lei no 2.119 que dispõe sobre multas por danos ambientais, estabelecendo normas para o depósito de lixo, tal medida pode ser considerada preventiva, uma vez que o objetivo é reduzir as irregularidades.

Referente ao município de Gabriel Monteiro, destaca-se que no ano 2014, foi instituído Programas de pagamento por serviços ambientais e recursos financeiros para a execução dos projetos. Segundo Wunder (2006 apud Jardim; Bursztyn, 2015, p. 353) "Entende-se por Pagamento por serviços ambientais as transferências financeiras de beneficiários de serviços ambientais para os que, devido a práticas que conservam a natureza, fornecem esses serviços, de forma segura e bem definida, por meio de uma transação voluntária."

O plano de gerenciamento de resíduos sólidos instituído pelo município de Gabriel Monteiro no ano de 2015, é de suma importância pois disponibiliza diretrizes e objetivos sobre a gestão dos resíduos, visto que muitas vezes o gerenciamento impróprio é ocasionado pela falta de informação e também pela falta de fiscalização. Por incluir ações relacionadas a Educação Ambiental e Cidade Sustentável, junto às diretrizes do Programa de Resíduos Sólidos apresenta-se como uma medida de adaptação.

No ano de 2016 foi criado o Conselho de Saneamento Ambiental, já que no ano de 2014 ficou instituído que seria necessário o controle social para acessar recursos da área.

\section{CONCLUSÃO}


Este artigo permitiu identificar a partir das leis e decretos, bem como dos planos municipais as ações de mitigação e adaptação e em qual das duas o governo municipal se propôs a fixar-se, colaborando, portanto, em sua pontuação no ranking de Município VerdeAzul.

As medidas mitigadoras, por serem medidas imediatas possuem um custo mais barato ao poder público e demandam um período de execução menor, são medidas rápidas, provavelmente o que permitiu que Bilac decaísse no ranking, devido algumas de suas leis terem o caráter de mitigar e não de adaptar. Já as de adaptação propõem uma solução eficaz e que extermine o problema por um período maior. Por envolver a elaboração e efetivação de projeto demandam tempo e custo elevado, embora os resultados durem mais. Gabriel Monteiro, portanto ao elaborar o Plano Municipal de Resíduos Sólidos contempla nesse projeto outras diretivas destacadas pela certificação, como educação ambiental, que a longo prazo permitem alterar e diminuir as relações conflituosas entre sociedade-ambiente.

\section{REFERÊNCIAS}

BILAC. Lei n. 1.909/2013, de 27 de junho de 2013. Institui o Plano Diretor de Arborização Urbana e dá outras providências.

BILAC. Lei n. 1.952/2013, de 23 de dezembro de 2013. Dispõe sobre a Política Municipal de Saneamento Ambiental e dá outras providências.

BILAC. Lei n. 1.956/2013, de 23 de dezembro de 2013. Institui o Código Municipal de Resíduos Sólidos e dá outras providências.

BILAC. Lei n. 2.058/2015, de 17 de março de 2015. Autoriza o Município celebrar convênio com o Estado de São Paulo, através da Secretaria de Saneamento e Recursos Hídricos, e dá outras providências.

BILAC. Lei n. 2.119/2016, de 7 de junho de 2016. Dispõe sobre multa por dano ambiental e dá outras providências.

CARVALHO, D.W. Instrumentos de prevenção a desastres: as medidas não estruturais e a construção de cidades resilientes. Revistas Novos Estudos Jurídicos, Itajaí, v.20,n.1,p.34-58, jan/abr. 2015.

GABRIEL MONTEIRO. Lei n. 1.820/2014, de 25 de agosto de 2014. Autoriza a Prefeitura Municipal de Gabriel Monteiro a instituir o "Programa Municipal de Pagamentos por Serviços Ambientais" e estabelecer convênios com o Estado de São Paulo para execução de projetos de pagamento por serviços ambientais.

GABRIEL MONTEIRO. Lei $\mathbf{n}$. 1.854/2015, de 10 de agosto de 2015 Institui o plano municipal de gerenciamento integrado de resíduos sólidos do município de Gabriel Monteiro - PMGRS e dá outras providências.

GABRIEL MONTEIRO. Projeto de lei n. 020/2016, de 12 de maio de 2016. Dispõe sobre a criação do conselho Municipal de Saneamento Ambiental e dá outras providências.

GOVERNO DE SÃO PAULO. Município VerdeAzul - Orientações do PMVA Ciclo 2016. Disponível em: http://arquivos.ambiente.sp.gov.br/municipioverdeazul/2011/11/PMVA-MANUAL.pdf. Acesso em 03 de agosto de 2017 
GIL, A.C. Como elaborar projetos de pesquisa. 4. ed. - São Paulo: Atlas, 2002.

JARDIM, M.H.; BURSZTYN, M.A. Pagamento por serviços ambientais na gestão de recursos hídricos: o caso de Extrema (MG). Engenharia Sanitária e Ambiental (Online), Scielo, v.20, n.3,p.353-360, jul/set. 2015.

LEFF, E. Epistemologia ambiental. São Paulo: Cortez, 2007

MARANDOLA JR., Eduardo. "A escolha de Sofia" ou o dilema da segurança humana nos desastres: qual agenda brasileira?. In: Norma Valencio; Mariana Siena. (Org.). Sociologia dos Desastres: construção, interfaces e perspectivas. São Carlos: RiMA, 2014. p. 91-108.

MENDONÇA, FRANCISCO. S.A.U. - Sistema ambiental urbano: uma abordagem dos problemas socioambientais da cidade. In: MENDONÇA, FRANCISCO (org). Impactos Socioambientais urbanos. Curitiba. PR. Editora UFPR, 2004. 185-207.

SÃO PAULO, Governo do Estado. Lei no 11.160, de 18 de junho de 2002. Dispõe sobre a criação do Fundo Estadual de Prevenção e Controle da Poluição - FECOP, e dá providências correlatas. Diário Oficial do Estado de São Paulo, São Paulo, SP. 19 de junho de 2002.

SMA - Secretaria do Meio Ambiental do Estado de São Paulo. Programa Município VerdeAzul. Disponível em: http://www.ambiente.sp.gov.br/municipioVerdeAzul. Acesso em: 03 de Agosto de 2017. 